\title{
The population impact of smoke-free workplace and hospitality industry legislation on smoking behaviour. Findings from a national population survey
}

Citation for published version (APA):

Nagelhout, G. E., Willemsen, M. C., \& de Vries, H. (2011). The population impact of smoke-free workplace and hospitality industry legislation on smoking behaviour. Findings from a national population survey. Addiction, 106(4), 816-823. https://doi.org/10.1111/j.1360-0443.2010.03247.x

Document status and date:

Published: 01/04/2011

DOI:

10.1111/j.1360-0443.2010.03247.x

Document Version:

Publisher's PDF, also known as Version of record

Document license:

Taverne

Please check the document version of this publication:

- A submitted manuscript is the version of the article upon submission and before peer-review. There can be important differences between the submitted version and the official published version of record.

People interested in the research are advised to contact the author for the final version of the publication, or visit the DOI to the publisher's website.

- The final author version and the galley proof are versions of the publication after peer review.

- The final published version features the final layout of the paper including the volume, issue and page numbers.

Link to publication

\footnotetext{
General rights rights.

- You may freely distribute the URL identifying the publication in the public portal. please follow below link for the End User Agreement:

www.umlib.nl/taverne-license

Take down policy

If you believe that this document breaches copyright please contact us at:

repository@maastrichtuniversity.nl

providing details and we will investigate your claim.
}

Copyright and moral rights for the publications made accessible in the public portal are retained by the authors and/or other copyright owners and it is a condition of accessing publications that users recognise and abide by the legal requirements associated with these

- Users may download and print one copy of any publication from the public portal for the purpose of private study or research.

- You may not further distribute the material or use it for any profit-making activity or commercial gain

If the publication is distributed under the terms of Article $25 \mathrm{fa}$ of the Dutch Copyright Act, indicated by the "Taverne" license above, 


\title{
The population impact of smoke-free workplace and hospitality industry legislation on smoking behaviour. Findings from a national population survey
}

\author{
Gera E. Nagelhout ${ }^{1,2}$, Marc C. Willemsen ${ }^{2,1}$ \& Hein de Vries' \\ Maastricht University/CAPHRI, Maastricht, the Netherlands' and STIVORO Dutch Expert Centre on Tobacco Control, The Hague, the Netherlands²
}

\begin{abstract}
Aims To study the impact of implementing smoke-free workplace and hospitality industry legislation on smoking behaviour. Design, setting and participants A cross-sectional population survey from 2001 to $2008(n \approx 18000$ per year) was used to assess trends and seasonal patterns in smoking and quitting, and to examine whether changes could be observed after the workplace smoking ban in the Netherlands in 2004 and the hospitality industry ban in 2008 . Measurements Outcome measures were smoking prevalence, quit attempts and successful quit attempts. Interactions with educational level (socio-economic status) and bar visiting (exposure to the hospitality industry ban) were tested. Findings The workplace ban was followed by a decrease in smoking prevalence (OR $=0.91, P<0.001)$, but the hospitality industry ban was not $(\mathrm{OR}=0.96, P=0.127)$. Both bans, especially the workplace ban, were followed by an increase in quit attempts and successful quit attempts: workplace ban, $\mathrm{OR}=1.31, P<0.001$; OR $=1.49, P<0.001$; hospitality industry ban, $\mathrm{OR}=1.13, P=0.013$; $\mathrm{OR}=1.44, P<0.001$. The workplace ban had a larger effect on successful quitting among higher-educated $(\mathrm{OR}=0.35, P<0.001)$ than on lower-educated respondents $(\mathrm{OR}=0.74$, $P=0.052)$. The hospitality industry ban had a larger effect on quit attempts among frequent bar visitors $(\mathrm{OR}=1.48$, $P=0.003)$ than on non-bar visitors $(\mathrm{OR}=0.71, P=0.014)$. Conclusions A workplace smoking ban in the Netherlands was followed by more changes in smoking and quitting than a hospitality industry ban. The hospitality industry ban only appeared to have an impact on quit attempts, and not on smoking prevalence.
\end{abstract}

Keywords Hospitality industry, Netherlands, seasonal patterns, smoking cessation, smoke-free laws, smoking prevalence, trends, workplace.

Correspondence to: Gera Nagelhout, STIVORO Dutch Expert Centre on Tobacco Control, PO Box 16070, 2500 BB The Hague, the Netherlands. E-mail: gnagelhout@stivoro.nl

Submitted 23 June 2010; initial review completed 22 September 2010; final version accepted 12 October 2010

\section{INTRODUCTION}

The Framework Convention on Tobacco Control (FCTC) was adopted in May 2003 under the auspices of the World Health Organization (WHO) [1]. Article 8 of the FCTC states that parties should adopt and implement national laws to protect citizens from exposure to secondhand smoke (SHS) in indoor public places. The Republic of Ireland was the first to implement a national law banning smoking from all enclosed workplaces, with very limited exemptions [2]. Only workplaces that were also private residences-hotel bedrooms, prisons, nursing homes and psychiatric hospitals-were exempted. Some of the countries that followed Ireland's example temporarily exempted the hospitality industry, because these workplaces also have an entertainment function for the general public and support for hospitality industry smoking bans is generally low; examples were Belgium, France and the Netherlands [3]. After a period in which the public could become used to smoke-free workplaces and in which the hospitality industry had the opportunity to create voluntary smoking bans, those countries extended the workplace smoking ban to the hospitality industry.

Implementing a workplace smoking ban first and a hospitality industry smoking ban later compromises the health of hospitality industry employees [2]. However, it is thought that this stepwise approach might also stimulate more smokers to quit smoking: first when the workplace ban is implemented and secondly when it is 
extended to the hospitality industry. According to the WHO, workplace smoking bans not only protect hospitality employees from exposure to SHS, but also encourages smokers to quit smoking [4]. Several studies found significant decreases in smoking prevalence after the implementation of a workplace ban [5-8]. Other studies found significant increases in smoking cessation [9-13]. In addition, a rise in the sales of nicotine replacement products $[14,15]$ and increased calls to smoking cessation quitlines [16-18] were found, suggesting an increase in smoking cessation. However, there were also studies that found no decline in smoking prevalence [18-20], while other studies found decreases in smoking prevalence too small to reach significance [21,22].

The above-cited studies evaluated the effects of workplace smoking bans on smoking and quitting, yet it appears that no research has examined the effects of an extension of a workplace ban to the hospitality industry. In this study we will assess the effects of the implementation of a workplace smoking ban in January 2004 in the Netherlands and the extension to the hospitality industry in July 2008.

When studying changes in smoking behaviour after the implementation of a smoking ban, trends in smoking behaviour should be taken into account [10,14,18]. For example, a decline in smoking can be ascribed to a smoking ban only when the decrease is larger than that of previous years. In this study we will relate a 7-year trend in smoking and quitting to the changes after the implementation of the workplace and hospitality industry smoking ban. Other policies that were implemented in this time-period were tax increases (2001, 2004 and 2008), text warning labels (2002), an advertising ban (2002) and a youth access law (2003). National mass media smoking cessation campaigns ran in 2003, 2004 and 2008. Our first hypothesis is that there will be fewer smokers and more quitters than normal after the implementation of the workplace and hospitality industry ban in the Netherlands.

Smoking is increasingly a problem for lower socioeconomic status (SES) groups [4]. There is some evidence that smoking bans have more impact on the smoking behaviour of higher SES groups $[6,10]$, while other studies did not find differences between SES groups $[12,13]$. Therefore, our second hypothesis is that we expect to observe more changes in smoking and quitting among people with a higher SES.

Since the Dutch smoking bans were implemented in conjunction with a tax increase and a mass media smoking cessation campaign, we could not simply assume that changes in smoking behaviour were due to the bans only. In other studies this issue was resolved by comparing individuals who were more and less exposed to the ban $[18,23,24]$. In this study we compared indi- viduals who were not exposed to the smoking ban in the hospitality industry (i.e. individuals who never visited bars) with individuals who were somewhat exposed to the ban (i.e. individuals who visited bars yearly), and those who were most exposed (i.e. individuals who visited bars monthly). Our third hypothesis is therefore that we expect to observe more changes in smoking and quitting among individuals who were more exposed to the ban.

\section{METHODS}

\section{Sample}

The data source for this study was the Dutch Continuous Survey of Smoking Habits (DCSSH). This is a crosssectional population survey of respondents aged 15 years and older that is used to monitor smoking habits of the Dutch population, using weekly measurements. The DCSSH is conducted by TNS NIPO (Amsterdam, the Netherlands) for the Dutch expert centre on tobacco control (STIVORO) and is supported by grants from the Dutch Ministry of Health. Respondents for the DCSSH were selected randomly from TNS NIPObase, a database with, at present, more than 140000 potential respondents who participate in internet-based research on a regular basis. TNS NIPObase panel members are recruited actively by TNS NIPO using telephone and mail. Data from the DCSSH from 2001 until 2008 were used for this study. Approximately 18000 respondents participated in the survey each year (144 733 in total from 2001 to 2008), with 18637 respondents in 2008 of whom 9572 were surveyed after the implementation of the smoking ban in July 2008. The data were representative of the Dutch population of 15 years and older after applying weights for gender, age, educational level, working hours, geographic region, urbanization and household size.

\section{Questionnaire}

The questionnaire used assessed background characteristics, smoking behaviour and use of smoking cessation aids, and contained extensive sections on attitudes towards smoking, quitting and tobacco control policies and campaigns. The questionnaire was sent to the respondents by e-mail. Respondents could complete the questionnaire at their own computer using software from TNS NIPO. For this study, questions about smoking behaviour and background characteristics from 2001 to 2008 were used.

In line with an earlier study [25], smoking status at the time of the survey was assessed by asking 'do you (ever) smoke or not at all?’. Respondents who answered that they smoke were defined as current smokers. Respondents who answered that they did not smoke were asked 'have you smoked in the past?'. Respondents who 
answered that they had smoked in the past were defined as former smokers and respondents who answered that they had not smoked in the past were defined as never smokers. Smoking prevalence was the percentage of respondents who were current smokers. This was calculated per year (for analyses between years) and per 6 months (for analyses within years).

Quit attempts in the last 6 and 12 months were measured by asking current smokers 'how long ago was your most recent attempt to quit smoking?' and by asking former smokers 'how long ago did you quit smoking?'. In line with earlier studies $[11,13]$, these questions were combined to construct dichotomous variables measuring (i) whether respondents made a quit attempt in the past year (for analyses between years) and (ii) whether respondents made a quit attempt in the past 6 months (for analyses within years).

Successful quit attempts in the last 6 and 12 months were measured with the same question as quit attempts, but excluding the current smokers (i.e. the unsuccessful quit attempts). This measure was also used in earlier studies [25,26].

Furthermore, age, gender, educational level, employment status and frequency of bar visiting were assessed. Age was categorized into four groups: 15-24 years, 25-39 years, 40-54 years and 55 years and older. Educational level was categorized into three groups: low (primary education and lower pre-vocational secondary education), medium (middle pre-vocational secondary education and secondary vocational education) and high (senior general secondary education, (pre-)university education and higher professional education). Employment status was categorized into currently employed and currently not employed for at least 2 days per week. Frequency of bar visiting was categorized as never, yearly and monthly visiting.

\section{Analyses}

The first hypothesis implies fewer smokers and more quitters than normal after the implementation of the workplace and hospitality industry smoking ban. To assess how much smoking and quitting was normal, we performed multivariate logistic regression analyses on data from 2001 to 2007. Dependent variables were percentage of smokers, percentage of quitters and percentage of successful quitters. Independent variables were 'year' for analyses to assess trends and 'period' (first 6 months and last 6 months of the year) to assess seasonal patterns. These analyses were repeated for 2003 and 2004 together (to assess trends following the implementation of the workplace smoking ban), 2004 only (to assess seasonal patterns following the workplace ban), 2007 and 2008 together (to assess trends following the hospitality industry ban) and 2008 only (to assess seasonal patterns following the hospitality industry ban).

The second hypothesis was that we expected to observe more changes in smoking and quitting among people with a higher SES. Educational level and income are common indicators of SES [27]. In this study, we used educational level as indicator of SES, because it contained considerably fewer missing values $(n=665)$ than income $(n=30661)$. Additional analyses on the respondents whose income was available resulted in similar conclusions as the analyses with educational level. The analyses for hypothesis 1 were repeated with educational level, and the interaction of educational level with year and period added as independent variables.

The third hypothesis states that the changes in smoking and quitting will be more pronounced among individuals who were more exposed to the hospitality industry ban. As a proxy of exposure to the ban we used frequency of bar visiting. The analyses for hypothesis 1 were repeated with frequency of bar visiting and the interaction of frequency of bar visiting with survey year and period added as independent variables.

All analyses were conducted with SPSS version 17 .

\section{RESULTS}

\section{Background characteristics}

There were no significant differences in background characteristics between survey years (Table 1). Also, the background characteristics did not differ between the pre- and post-ban periods in 2008. More frequent bar visitors were significantly younger $\left(\chi^{2}=5726.48, P<0.001\right)$, more often male $\left(\chi^{2}=336.69, P<0.001\right)$, higher educated $\left(\chi^{2}=3018.78, P<0.001\right)$ and more often employed $\left(\chi^{2}=2447.60, P<0.001\right)$.

\section{Differences in smoking and quitting between 2001 and 2008}

Figure 1 shows smoking prevalence, percentage of quit attempts and percentage of successful quit attempts from 2001 to 2008. Table 2 shows that smoking prevalence significantly decreased in the 2001-07 period [odds ratio $(\mathrm{OR})=0.97, P<0.001]$. This decrease was larger in $2004(\mathrm{OR}=0.91, P<0.001)$, after the workplace smoking ban had been implemented. Smoking prevalence declined from $29.9 \%$ in 2003 to $27.9 \%$ in 2004 . In 2008, when the hospitality industry smoking ban was implemented, the observed decrease from $27.5 \%$ to $26.7 \%$ was not significant $(\mathrm{OR}=0.96, P=0.127)$. There was no significant seasonal pattern in smoking prevalence in the 2001-07 period ( $\mathrm{OR}=1.00, P=0.726)$. In 2004 , there was a significant difference between smoking prevalence in the first and second halves of the year. In 
Table 1 Background characteristics from 2001 to 2008 (weighted data).

\begin{tabular}{|c|c|c|c|c|c|c|c|c|}
\hline & 2001 & 2002 & 2003 & 2004 & 2005 & 2006 & 2007 & 2008 \\
\hline \multicolumn{9}{|l|}{ Age (years) } \\
\hline $15-24$ & 14.7 & 14.7 & 14.7 & 14.7 & 14.7 & 14.7 & 14.7 & 14.7 \\
\hline $25-39$ & 29.9 & 30.3 & 30.3 & 30.6 & 30.3 & 30.3 & 30.7 & 30.8 \\
\hline $40-54$ & 26.9 & 26.5 & 26.5 & 26.3 & 26.4 & 26.5 & 26.1 & 26.0 \\
\hline \multicolumn{9}{|l|}{ Gender } \\
\hline Men & 49.1 & 49.1 & 49.1 & 49.2 & 49.1 & 49.1 & 49.1 & 49.0 \\
\hline Women & 50.9 & 50.9 & 50.9 & 50.8 & 50.9 & 50.9 & 50.9 & 51.0 \\
\hline \multicolumn{9}{|c|}{ Educational level } \\
\hline Low & 44.4 & 44.5 & 44.4 & 44.5 & 44.4 & 44.5 & 44.5 & 44.5 \\
\hline Medium & 33.6 & 33.6 & 33.6 & 33.6 & 33.6 & 33.6 & 33.6 & 33.6 \\
\hline High & 22.0 & 22.0 & 22.0 & 21.9 & 21.9 & 21.9 & 21.9 & 21.9 \\
\hline \multicolumn{9}{|l|}{ Employment ${ }^{\mathrm{a}}$} \\
\hline Yes & - & - & - & - & 70.6 & 70.4 & 70.9 & 70.8 \\
\hline No & - & - & - & - & 29.4 & 29.6 & 29.1 & 29.2 \\
\hline \multicolumn{9}{|c|}{ Frequency of bar visiting ${ }^{a}$} \\
\hline Monthly & - & - & - & - & - & 22.9 & 23.5 & 22.8 \\
\hline Yearly & - & - & - & - & - & 29.5 & 29.6 & 30.8 \\
\hline Never & - & - & - & - & - & 47.7 & 46.9 & 46.4 \\
\hline
\end{tabular}

aData on employment and frequency of bar visiting was collected from 2005 and 2006, respectively.

Figure I Trends in smoking and quitting

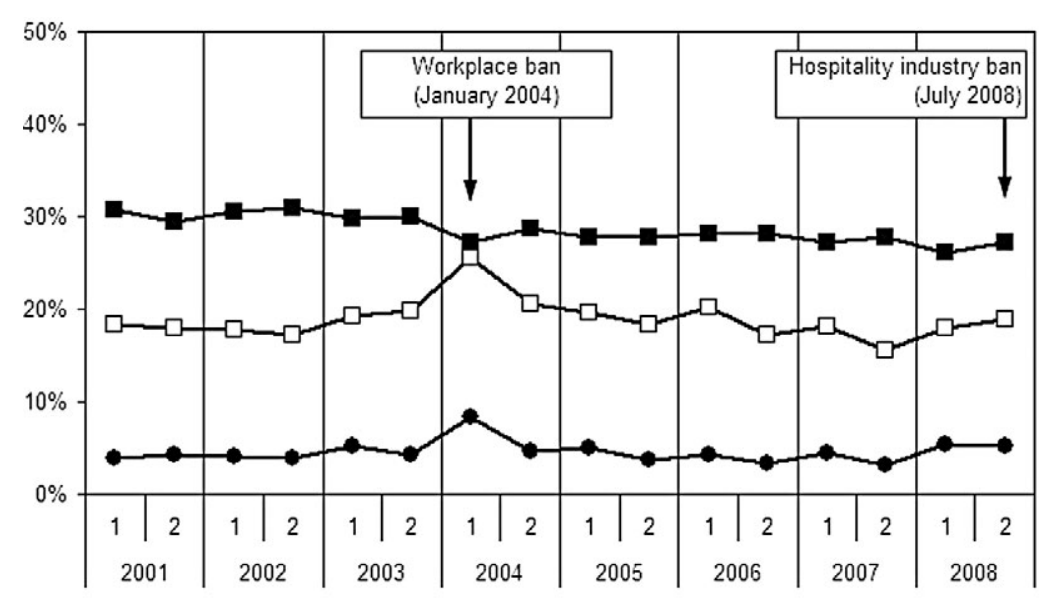
between $200 \mathrm{I}$ and 2008

- Smoking prevalence $\rightarrow \square-$ Quit attempts $\rightarrow-$ Successful quit attempts

Table 2 Logistic regression analyses: trends and seasonal patterns in smoking and quitting between 2001 and 2008, odds ratios (OR) with $95 \%$ confidence intervals $(\mathrm{CI})$ and $P$-values.

\begin{tabular}{|c|c|c|c|c|c|c|}
\hline & \multicolumn{2}{|l|}{ Smoking prevalence } & \multicolumn{2}{|l|}{ Quit attempts } & \multicolumn{2}{|c|}{ Successful quit attempts } \\
\hline & OR $(95 \% C I)$ & $P$ & OR $(95 \% C I)$ & $P$ & OR $(95 \% C I)$ & $P$ \\
\hline \multicolumn{7}{|l|}{ Trends } \\
\hline 2001-2007 & $0.97(0.97-0.98)$ & $<0.001$ & $1.00(0.99-1.01)$ & 0.759 & $0.99(0.97-1.01)$ & 0.286 \\
\hline 2003-2004 & $0.91(0.87-0.95)$ & $<0.001$ & $1.31(1.21-1.41)$ & $<0.001$ & $1.49(1.31-1.70)$ & $<0.001$ \\
\hline 2007-2008 & $0.96(0.92-1.01)$ & 0.127 & $1.13(1.03-1.23)$ & 0.013 & $1.44(1.22-1.69)$ & $<0.001$ \\
\hline \multicolumn{7}{|c|}{ Seasonal patterns } \\
\hline 2001-2007 & $1.00(0.98-1.03)$ & 0.726 & $0.90(0.85-0.94)$ & $<0.001$ & $0.77(0.70-0.85)$ & $<0.001$ \\
\hline 2004 & $1.08(1.01-1.15)$ & 0.023 & $0.75(0.66-0.85)$ & $<0.001$ & $0.54(0.44-0.68)$ & $<0.001$ \\
\hline 2008 & $1.05(0.98-1.12)$ & 0.147 & $1.07(0.93-1.23)$ & 0.359 & $0.96(0.75-1.22)$ & 0.722 \\
\hline
\end{tabular}


the second half of 2004, smoking prevalence was significantly higher than in the first half $(\mathrm{OR}=1.08$, $P=0.023)$. In 2008, smoking prevalence did not differ significantly between the first and second halves of the year $(\mathrm{OR}=1.05, P=0.147)$. Therefore, we can conclude that the workplace smoking ban was followed by a decline in smoking prevalence, but the hospitality industry smoking ban was not.

The analyses in Table 2 show no trends in the percentage of quit attempts in the 2001-07 period (OR $=1.00$, $P=0.759)$. In 2004 there were significantly more quit attempts (33.3\%) than in $2003(27.7 \%)(\mathrm{OR}=1.31$, $P<0.001)$. In 2008 there were also significantly more quit attempts (26.3\%) than in $2007(24.1 \%)(O R=1.13$, $P=0.013)$. There was a significant seasonal pattern in the percentage of quit attempts between 2001 and 2007 $(\mathrm{OR}=0.90, P<0.001)$. In the second half of the years there were fewer quit attempts than in the first half of the years. This pattern was stronger in $2004(\mathrm{OR}=0.75$, $P<0.001)$ and absent in $2008(\mathrm{OR}=1.07, P=0.359)$. This means that the workplace smoking ban especially, but also the hospitality industry ban, was followed by an increase in quit attempts.

From Table 2 it follows that there was no trend in the percentage of successful quit attempts between 2001 and 2007 (OR = 0.99, $P=0.286$ ). However, there was a significant increase from $6.9 \%$ successful quit attempts in 2003 to $10.0 \%$ in 2004 ( $O R=1.49, P<0.001)$. There was also a significant increase from $5.6 \%$ in 2007 to $8.0 \%$ in $2008(\mathrm{OR}=1.44, \mathrm{P}<0.001)$. There was a seasonal pattern with fewer successful quit attempts in the second half than in the first half of the years $(\mathrm{OR}=0.77$, $P<0.001)$. In 2004 this pattern was stronger $(\mathrm{OR}=$ $0.54, P<0.001)$, whereas in 2008 it was absent $(\mathrm{OR}=0.96, P=0.722)$. The conclusion is that the workplace smoking ban in particular, but also the hospitality industry ban, was followed by an increase in successful quit attempts.

\section{Interaction effects with educational level}

In 2004 a significant interaction with educational level was found in the seasonal pattern of more successful quit attempts in the first half of 2004 compared to the second half $(\mathrm{OR}=0.64, P=0.004)$. This pattern was stronger for higher-educated $(\mathrm{OR}=0.35, P<0.001)$ than for medium-educated $(\mathrm{OR}=0.41, P<0.001)$ and lowereducated respondents $(\mathrm{OR}=0.74, P=0.052)$. This difference in seasonal patterns between educational levels was not prevalent between 2001 and 2007. In 2008 there were no significant interactions with educational level in trends or seasonal patterns.

\section{Interaction effects with bar visiting in 2007 and 2008}

There were no significant interactions with bar visiting in trends in smoking and quitting between 2007 and 2008. A significant interaction with bar visiting was found in the seasonal pattern in quit attempts in 2008 $(\mathrm{OR}=1.43, \mathrm{P}<0.001)$. Monthly bar visitors were significantly more likely to attempt to quit smoking in the second half of 2008 than in the first half $(\mathrm{OR}=1.48$, $P=0.003)$; yearly bar visitors were not more or less likely to quit ( $\mathrm{OR}=1.25, P=0.116$ ); and non-bar visitors were significantly less likely to quit in the second half of 2008 $(\mathrm{OR}=0.71, P=0.014)$. This difference in seasonal pattern between monthly, yearly and non-bar visitors was not prevalent in 2007.

The univariate analyses in Table 3 reveal that attempting to quit smoking and bar visiting were unrelated before the implementation of the hospitality industry ban in $2008\left(\chi^{2}=0.28, P=0.876\right)$, while they were related significantly after the implementation $\left(\chi^{2}=31.00, P=0.001\right)$. Monthly bar visitors attempted to quit smoking almost twice as often as non-bar visitors (25\% and $14 \%$, respectively) post-ban. When controlling for background variables in a multivariate logistic regression analysis with the 'enter' method, attempting to quit smoking and bar visiting were unrelated pre-ban (Table 4). Post-ban, bar visitors were more likely to attempt to quit smoking. When conducting a multivariate logistic regression analysis with the 'forward' method (not shown), a model was fitted with age as the only predictor of attempting to quit smoking pre-ban and both age and bar visiting as predictors of attempting to quit smoking post-ban.

\section{DISCUSSION}

Previous research found that a workplace smoking ban may lead to fewer smokers [5-8] and more quitters [9-13]. However, there were no studies available about

Table 3 Comparison of quit attempts by frequency of bar visiting pre-ban and post-ban in 2008 .

\begin{tabular}{llllr}
\hline & $\begin{array}{l}\text { Non-bar visitors } \\
(\%)\end{array}$ & $\begin{array}{l}\text { Yearly bar visitors } \\
(\%)\end{array}$ & $\begin{array}{l}\text { Monthly bar visitors } \\
(\%)\end{array}$ & $\chi^{2}$ \\
\hline January-June 2008 (pre-ban) & 18.3 & 17.5 & 18.5 & 0.28 \\
July-December 2008 (post-ban) & 13.8 & 20.9 & 25.1 & 31.00 \\
\hline
\end{tabular}


Table 4 Logistic regression analyses: factors associated with attempting to quit smoking pre-ban and post-ban in 2008, odds ratios (OR) with 95\% confidence intervals (CI) and P-values.

\begin{tabular}{|c|c|c|c|c|}
\hline & \multicolumn{2}{|c|}{ January-June 2008 (pre-ban) $(n=1893)$} & \multicolumn{2}{|c|}{ July-December 2008 (post-ban) $(n=1950)$} \\
\hline & OR $(95 \% C I)$ & $P$ & OR $(95 \% \mathrm{CI})$ & $P$ \\
\hline \multicolumn{5}{|l|}{ Age (years) } \\
\hline $15-24$ & $2.05(1.26-3.31)$ & 0.004 & $1.89(1.17-3.05)$ & 0.010 \\
\hline $25-39$ & $1.09(0.72-1.64)$ & 0.679 & $1.25(0.85-1.85)$ & 0.256 \\
\hline $40-54$ & $0.81(0.55-1.21)$ & 0.306 & $0.81(0.54-1.20)$ & 0.840 \\
\hline 55 and older & $1.0(-)$ & & $1.0(-)$ & \\
\hline \multicolumn{5}{|l|}{ Gender } \\
\hline Men & $0.88(0.69-1.12)$ & 0.310 & $1.02(0.82-1.29)$ & 0.840 \\
\hline Women & $1.0(-)$ & & $1.0(-)$ & \\
\hline \multicolumn{5}{|c|}{ Educational level } \\
\hline Low & $0.77(0.56-1.07)$ & 0.116 & $0.70(0.51-0.95)$ & 0.022 \\
\hline Medium & $0.79(0.57-1.08)$ & 0.142 & $0.93(0.69-1.25)$ & 0.635 \\
\hline High & $1.0(-)$ & & $1.0(-)$ & \\
\hline \multicolumn{5}{|l|}{ Employment } \\
\hline Yes & $0.93(0.66-1.31)$ & 0.668 & $1.03(0.74-1.44)$ & 0.852 \\
\hline No & $1.0(-)$ & & $1.0(-)$ & \\
\hline \multicolumn{5}{|c|}{ Frequency of bar visiting } \\
\hline Monthly & $0.85(0.61-1.18)$ & 0.328 & $1.45(1.07-1.97)$ & 0.018 \\
\hline Yearly & $1.01(0.75-1.37)$ & 0.955 & $1.41(1.05-1.89)$ & 0.023 \\
\hline Never & $1.0(-)$ & & $1.0(-)$ & \\
\hline
\end{tabular}

the potential added effect of the extension of a workplace smoking ban to the hospitality industry. We hypothesized that there would be fewer smokers and more quitters than normal after the implementation of the smoking bans in the Netherlands. Therefore, we had to assess first which pattern of smoking and quitting was normal. We found that smoking prevalence decreased from 2001 until 2007 and that there were no seasonal variations between the first and second halves of the year. The percentage of quit attempts and successful quit attempts was stable from 2001 until 2007, but it was higher in the first than in the second halves of most years. This pattern was also found in earlier studies $[13,28,29]$ and can probably best be explained by New Year resolutions.

We found fewer smokers than normal after the implementation of the workplace ban, and increases in quit attempts and successful quit attempts. In contrast, we did not find fewer smokers than normal after the hospitality industry smoking ban, and smaller increases in quit attempts and successful quit attempts. We can therefore conclude that a workplace ban is followed by more changes in smoking and quitting than a hospitality industry ban.

Our second hypothesis was that we expected to observe more changes in smoking and quitting after the implementation of the bans among those with a higher SES. We found more successful quitting among higher-educated respondents after the workplace ban, but we did not find this after the hospitality industry ban. It is an encouraging finding that hospitality industry smoking bans have the potential to increase smoking cessation in both higher and lower educational groups.

Our third hypothesis was that we expected to observe more changes in smoking and quitting among individuals who were more exposed to the hospitality industry ban. This hypothesis was supported, in that we found fewer quit attempts post-ban than pre-ban for non-bar visitors (the normal pattern) and more quit attempts post-ban than pre-ban for frequent bar visitors. Also, we found that respondents who visited bars more frequently more often attempted to quit smoking than non-bar visitors post-ban, whereas this pattern could not be observed pre-ban. This implies that the increase in quit attempts after the implementation of the hospitality industry ban is at least partly a consequence of the ban.

Our study does not explain why smoking bans affect smoking behaviour. Workplace bans are often thought to limit smoking behaviour by curtailing smoking opportunities $[9,30]$. This may not apply to a hospitality industry ban, as people spend less time in bars than in workplaces, and can choose to leave or smoke outside whenever they want to. Other explanations for the effects of smoking bans on smoking behaviour are that the ban increases the social stigma attached to smoking [5,30], leads to less socially cued smoking $[18,31]$ and raises awareness of the dangers of smoking [7]. It is conceivable that the hospitality industry ban in the Netherlands did not lead to more 
social stigma regarding smoking and to less socially cued smoking, because of the far less than optimal compliance in bars [32]. It is also possible that the ban failed to increase awareness of the dangers of smoking, because the implementation campaign by the Dutch government focused only on the date of implementation and not on the public health reasons for the ban. What remains is that smokers may have been triggered to use the implementation date as their quit date [18]. There was also a mass media campaign in the period around the implementation of the ban that encouraged attempts to quit smoking. Anecdotal evidence from smoking cessation counsellors suggests that smokers postponed their quit attempts until the date of the introduction of the smoking ban, because they expected that smoke-free bars would help them to stay off tobacco. When numerous bars did not comply with the ban, many were disappointed and gave up on their quit attempt. This might explain why we found that the ban only generated quit attempts and did not cause more lasting effects. These results may therefore not be generalizable to other countries with better compliance. We recommend strong enforcement of smoking bans and combining the introduction of the ban with offering smokers help in staying quit.

A limitation of this study was that the impact of smoking bans could not be assessed separately from the impact of tax increases and mass media campaigns, as these measures were implemented simultaneously. Furthermore, the trend in smoking behaviour from 2001 to 2007 was used to examine whether smoking behaviour in 2008 was different than normal. Another approach would be to compare smoking behaviour between 2008 and 2009. Unfortunately, we could not compare 2008 with 2009, as changes in the sampling strategy of the survey caused considerable differences in the background characteristics of respondents from 2009. In this study we used a large cross-sectional population survey with continuous measures throughout the year with respondents who were representative for the Dutch population. The advantage of this large data set was that small changes in smoking behaviour could be detected and generalized to the population. A disadvantage is the cross-sectional nature of the data. Consequently, we were not able to draw conclusions about causal relationships. Future research with longitudinal data is therefore recommended.

\section{Declarations of interest}

The authors have no conflicts of interest.

\section{Acknowledgements}

The Dutch Continuous Survey of Smoking Habits was supported by grants from the Dutch Ministry of Health, Welfare and Sport.

\section{References}

1. World Health Organization. WHO Framework Convention on Tobacco Control. Geneva, Switzerland: World Health Organization; 2003.

2. Smoke Free Partnership. Lifting the Smokescreen. 10 Reasons for a Smoke Free Europe. Brussels: European Respiratory Society Brussels Office; 2006.

3. European Network for Smoking Prevention (ENSP). European trends towards smoke-free provisions. Brussels: European Network for Smoking Prevention 2009.

4. World Health Organization. Report on the Global Tobacco Epidemic, 2008: the MPOWER Package. Geneva: World Health Organization; 2008.

5. Gallus S., Zuccaro P., Colombo P., Apolone G., Pacifici R., Garattini S. et al. Smoking in Italy 2005-2006: effects of a comprehensive national tobacco regulation. Prev Med 2007; 45: 198-201.

6. Farrelly M. C., Evans W. N., Sfekas A. E. S. The impact of workplace smoking bans: results from a national survey. Tob Control 1999; 8: 272-7.

7. Hahn E. J., Rayens M. K., Butler K. M., Zhang M., Durbin E., Steinke D. Smoke-free laws and adult smoking prevalence. Prev Med 2008; 47: 206-9.

8. Lemstra M., Neudorf C., Opondo J. Implications of a public smoking ban. Can J Public Health 2008; 99: 62-5.

9. Longo D. R., Johnson J. C., Kruse R. L., Brownson R. C., Hewett J. E. A prospective investigation of the impact of smoking bans on tobacco cessation and relapse. Tob Control 2001; 10: 267-72.

10. Fowkes F. J. I., Stewart M. C. W., Fowkes F. G. R., Amos A., Price J. F. Scottish smoke-free legislation and trends in smoking cessation. Addiction 2008; 103: 1888-95.

11. Farkas A. J., Gilpin E. A., Distefan J. M., Pierce J. P. The effects of household and workplace smoking restrictions on quitting behaviours. Tob Control 1999; 8: 261-5.

12. Moskowitz J., Lin Z., Hudes E. The impact of workplace smoking ordinances in California on smoking cessation. Am J Public Health 2000; 90: 757-61.

13. Hackshaw L., McEwen A., West R., Bauld L. Quit attempts in response to smoke-free legislation in England. Tob Control 2010; 19: 160-4.

14. Lewis S. A., Haw S. J., McNeill A. The impact of the 2006 Scottish smoke-free legislation on sales of nicotine replacement therapy. Nicotine Tob Res 2008; 10: 1789-92.

15. Galeone D., Laurendi G., Vasselli S., Spizzichino L., D'Argenio P., Greco D. Preliminary effects of Italy's ban on smoking in enclosed public places. Tob Control 2006; 15 : 143.

16. Chan S. S. C., Wong D. C. N., Fong D. Y. T., Leung A. Y. M., Mak Y. W., Lam D. O. B. et al. Short-term impact of new smoke-free legislation on the utilization of a quitline in Hong Kong. Nicotine Tob Res 2009; 11: 356-61.

17. Wilson N., Thomson G., Grigg M., Afzal R. New smoke-free environments legislation stimulates calls to a national Quitline. Tob Control 2005; 14: 287-8.

18. Edwards R., Thomson G., Wilson N., Waa A., Bullen C., O'Dea D. et al. After the smoke has cleared: evaluation of the impact of a new national smoke-free law in New Zealand. Tob Control 2008; 17: e2.

19. Elton P. J., Campbell P. Smoking prevalence in a north-west town following the introduction of Smoke-free England. J Public Health 2008; 30: 415-20. 
20. Galan I., Mata N., Estrada C., Diez-Ganan L., Velazquez L. Zorrilla B. et al. Impact of the 'Tobacco control law' on exposure to environmental tobacco smoke in Spain. BMC Public Health 2007; 7: 224.

21. Haw S. J., Gruer L. Changes in exposure of adult nonsmokers to secondhand smoke after implementation of smoke-free legislation in Scotland: national cross sectional survey. BMJ 2007; 335: 549-52.

22. Mullally B. J., Greiner B. A., Allwright S., Paul G., Perry I. J. The effect of the Irish smoke-free workplace legislation on smoking among bar workers. Eur J Public Health 2009; 19: 206-11.

23. Verdonk-Kleinjan W. M. I., Knibbe R. A., Tan F. E. S., Willemsen M., De Groot H. N., De Vries H. Does the workplace-smoking ban eliminate differences in risk for environmental tobacco smoke exposure at work. Health Policy 2009; 92: 197-202.

24. Braverman M. T., Aaro L. E., Hetland J. Changes in smoking among restaurant and bar employees following Norway's comprehensive smoking ban. Health Promot Int 2008; 23: 5-15.

25. Willemsen M. C., Hoogenveen R. T., Van der Lucht F. New smokers and quitters. Transitions in smoking status in a national population. Eur J Public Health 2002; 12: 136-8.
26. Capannesi M., Boshuizen H. C., Willemsen M. C., Van Houwelingen H. C. How to obtain long term projections for smoking behaviour: a case study in the Dutch population. Comput Math Methods Med 2009; 10: 155-64.

27. Huisman M., Kunst A. E., Mackenbach J. P. Inequalities in the prevalence of smoking in the European Union: comparing education and income. Prev Med 2005; 40: 756-64.

28. Chandra S., Chaloupka F. J. Seasonality in cigarette sales: patterns and implications for tobacco control. Tob Control 2003; 12: 105-7.

29. Momperousse D., Delnevo C. D., Lewis M. J. Exploring the seasonality of cigarette-smoking behaviour. Tob Control 2007; 16: 69-70.

30. Levy D. T., Friend K. B. The effects of clean indoor air laws: what do we know and what do we need to know. Health Educ Res 2003; 18: 592-609.

31. Trotter L., Wakefield M., Borland R. Socially cued smoking in bars, nightclubs, and gaming venues: a case for introducing smoke-free policies. Tob Control 2002; 11: 300-4.

32. International Tobacco Control (ITC) Project. ITC Netherlands National Report. Waterloo, The Hague: University of Waterloo, STIVORO; 2010. 